\title{
Experiências de formação inicial e atuação profissional do professor supervisor de estágio curricular supervisionado em educação física ${ }^{1}$
}

\section{Experiences of initial training and professional practice the supervised curricular internship teacher in physical education}

Experiencias de formación inicial y actuacion profesional de profesores supervisores de práctica curricular supervisada en educación física

\author{
iD (9) Ayla Cristine Gonçalves \\ Universidade Estadual do Oeste do Paraná (Unioeste), Marechal Cândido Rondon, \\ Paraná, Brasil. \\ e-mail: aylacristinegoncalves@hotmail.com \\ iD (9) Adelar Aparecido Sampaio \\ Universidade Estadual do Oeste do Paraná (Unioeste), Marechal Cândido Rondon, \\ Paraná, Brasil. \\ e-mail: adelarsampaio@hotmail.com \\ (iD) Evandra Hein Mendes \\ Universidade Estadual do Oeste do Paraná (Unioeste), Marechal Cândido Rondon, \\ Paraná, Brasil. \\ e-mail: evandrahmendes@hotmail.com \\ iD Arestides Pereira da Silva Júnior \\ Universidade Estadual do Oeste do Paraná (Unioeste), Marechal Cândido Rondon, \\ Paraná, Brasil. \\ e-mail: arestidesjunior2000@yahoo.com.br
}

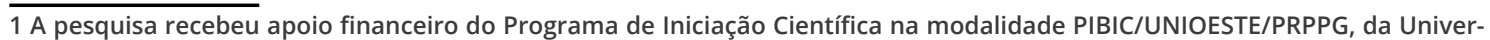
sidade Estadual do Oeste do Paraná.
} 
Resumo: O artigo objetivou apresentar uma análise e discussão sobre o papel do professor supervisor de Educação Física a partir de experiências formativas e de atuação na realização do estágio curricular supervisionado em escolas públicas de Marechal Cândido Rondon-PR. A pesquisa caracteriza-se como exploratória com abordagem quali-quantitativa, tendo o questionário como instrumento para coleta de dados. Constatou-se que os professores tiveram boas experiências em relação ao estágio durante a sua graduação, e eles apresentaram uma avaliação consensual positiva sobre a sua importância na formação docente. também alertaram não ter uma capacitação específica para atuar nessa função, mas destacaram as suas experiências profissionais como elementos que os habilitam a exercerem o papel de professor supervisor.

Palavras-Chave: Estágio Supervisionado. Professor Supervisor. Docência. Educação Física.

Abstract: The article aimed to present an analysis and discussion about the role of the Physical Education supervising professor, based on formative and acting experiences in the execution of the supervised curricular internship in public schools in Marechal Cândido RondonPR. The research is characterized as exploratory with a qualitative and quantitative approach, with the questionnaire as the instrument for data collection. It was found that the teachers had good experiences in relation to the internship during their graduation and present a positive consensual assessment of its importance in teacher education. They also warned that they did not have specific training to work in this role, but highlighted their professional experiences as elements that enable them to exercise the role of supervising teacher.

Keywords: Supervised internship. Supervising Teacher. Teaching. Physical Education.

Resumen: El artículo tuvo como objetivo presentar un análisis y discusión sobre el rol del maestro supervisor de Educación Física, basado en experiencias formativa y actuación en la práctica curricular supervisada en escuelas públicas de Marechal Cândido Rondon-PR. La investigación 
se caracteriza por ser exploratoria con enfoque cualitativo y cuantitativo, con el cuestionario como instrumento de recolección de datos. Se encontró que los docentes tuvieron buenas experiencias en relación a la pasantía durante su graduación y presentan una valoración consensuada positiva de su importancia en la formación docente. También advirtieron que no cuentan con una formación específica para desempeñar este rol, pero destacaron sus experiencias profesionales como elementos que les habilitan para ejercer el rol de docente supervisor.

Palabras clave: Práctica Curricular Supervisada. Profesor Supervisor. Enseñando. Educación Física.

Submetido em: 15-09-2020

Aceito em: 08-06-2021 
Experiências de formação inicial e atuação profissional do professor supervisor de estágio... Ayla Cristine Gonçalves • Adelar Aparecido Sampaio • Evandra Hein Mendes • Arestides Pereira da Silva Júnior

\section{Introdução}

Embora o processo de constituição de sua profissionalidade e a aquisição de saberes docentes antecedam o início da vida acadêmica, é na formação inicial que o futuro docente adquire e organiza os conhecimentos específicos de sua atuação profissional, sendo esta, preferivelmente, contínua e permanente (TARDIFF, 2014).

Nesse âmbito de formação, o Estágio Curricular Supervisionado (ECS) se torna um espaço indispensável, pois é um dos primeiros contatos do futuro professor com o campo profissional (escola), gerando, em alguns momentos, um choque entre a realidade da formação acadêmica e o ambiente escolar (PIMENTA; LIMA, 2012; COSTA FILHO, 2014). É nesse espaço que o processo de formação inicial se revela fundamental, pois é a partir dele que os futuros docentes irão adquirir os conhecimentos elementares para sua atuação, sendo um período de enredamento de referenciais pessoais e profissionais que vão se moldando na vida do potencial futuro professor (SAMPAIO et al., 2019), além de ser reconhecido como o período de desenvolvimento de atitudes, ações, reflexões e do seu próprio projeto profissional (SAMPAIO; STOBAUS, 2015).

Moraes et al. (2008) afirmam que, na formação de professores, é preciso que o futuro docente entenda o ECS como um processo que transcenda contatos pontuais com a escola, percebendo essa ação para além do cumprimento de tarefas curriculares. Assim, o estagiário deve ser considerado como protagonista consciente na sua atuação, de forma que as ações desenvolvidas ao longo desse processo educativo valorizem uma postura crítica e reflexiva no exercício de suas ações teórico-práticas no contexto escolar (SILVA JÚNIOR et al., 2016).

Sob esse prisma, Pimentel e Pontuschka (2014) reiteram que o ECS deve proporcionar uma relação integrada entre o processo formativo e a realidade escolar, favorecendo uma maior proximidade entre os agentes da escola e os da universidade. Dessa forma, estimulará a troca de conhecimentos e experiências entre os 
Experiências de formação inicial e atuação profissional do professor supervisor de estágio... Ayla Cristine Gonçalves • Adelar Aparecido Sampaio • Evandra Hein Mendes • Arestides Pereira da Silva Júnior

agentes envolvidos com o Ensino Superior e a Educação Básica, sobretudo nas relações entre os estagiários (futuros professores), o professor orientador (professor da universidade) e o professor supervisor ${ }^{2}$ (professor da escola).

Nesse contexto, de acordo com Benites (2012), o professor supervisor é um agente fundamental nesse processo e tem a função de favorecer o desenvolvimento das competências relacionadas ao trabalho com os alunos, como a comunicação e a detecção da realidade. Esse profissional oferece aos futuros professores elementos da sua experiência, possibilitando que eles descubram a importância da profissão e, concomitantemente, oferece oportunidades para colocarem em prática seus conhecimentos didático-pedagógicos.

Benites et al. (2012) revelam que os professores supervisores ocupam um lugar privilegiado durante o momento do estágio, mas que, na maioria das vezes, não se sentem suficientemente preparados para auxiliar e atuar no contexto da formação de novos docentes, tendo em vista que não foram preparados e capacitados para isso, uma vez que a sua formação na graduação foi direcionada para o ensino dos alunos da Educação Básica. No entanto, por serem os agentes que conhecem e vivenciam o cotidiano da escola e das especificidades aplicadas da Educação Física escolar, eles podem, e muito, contribuir para a formação dos futuros professores (BENITES, 2012).

Contudo, quando esse processo de supervisão pelo professor da escola não ocorre de forma efetiva ou apresenta fragilidades no acompanhamento e orientação, seja por fatores de falta de organização e/ou estruturação das ações ligadas ao ECS, da ausência de processos integrados entre os agentes envolvidos ou até mesmo a falta de clareza/domínio sobre as funções do professor supervisor, tais aspectos poderão refletir de forma negativa na efetividade do estágio (BENITES et al., 2012; RESENDE et al., 2013; SILVA JÚNIOR, 2016; SILVEIRA; BATISTA; PEREIRA, 2014; TELLES et

\footnotetext{
2 Embora na literatura existem outras denominações, como professores colaboradores, cooperadores, regentes de turma, dentre outros, neste artigo, será utilizado o termo professor supervisor para referir-se ao docente da escola, responsável pelo processo de acompanhamento do acadêmico ao longo do ECS.
} 
Experiências de formação inicial e atuação profissional do professor supervisor de estágio... Ayla Cristine Gonçalves • Adelar Aparecido Sampaio • Evandra Hein Mendes • Arestides Pereira da Silva Júnior

al., 2015). Considerando a complexidade e riqueza do processo de ECS, essa limitação apresentada reforça a ideia de um processo formativo unilateral exposta por Pimenta e Lima (2012), na qual os conhecimentos da universidade são sobrepostos ao da escola e, com isso, acaba por fragmentar ainda mais as compreensões dos universos acadêmico e profissional.

Nesse cenário, destaca-se a necessidade de uma atuação integrada entre todas as partes envolvidas, no intuito de minimizar os efeitos da adaptação e possibilitar ao estagiário condições adequadas para que possa exercer a sua prática com efetividade e direcionamento para atingir os objetivos propostos pelo estágio (NEIRA, 2012; AROEIRA, 2014; SILVA JÚNIOR, 2016).

Nos últimos anos, pesquisas sobre o papel do professor supervisor de Educação Física (EF) começam a receber maior interesse por pesquisadores da área e se destacam no cenário acadêmico (BENITES, 2012; BENITES et al., 2012; BENITES; CYRINO; SOUZA NETO, 2013; SILVEIRA; BATISTA; PEREIRA, 2014; TELLES et al., 2015; SILVA JÚNIOR; OLIVEIRA, 2018), reforçando a importante contribuição formativa desse profissional no ECS, em consonância com os demais agentes e indivíduos envolvidos nesse processo (professores orientadores, direção, coordenação pedagógica, alunos, demais professores e funcionários).

No entanto, apesar da realização de pesquisas com foco no professor supervisor de ECS na EF, não foram encontradas investigações que considerassem, ao mesmo tempo, as experiências formativas e de atuação do professor supervisor. Nesse sentido, o objetivo dessa investigação centra-se em analisar as experiências formativas e de atuação de professores de EF de escolas públicas de Marechal Cândido Rondon-PR, na supervisão de estágios nessa área.

Como forma de ampliar o olhar sobre o fenômeno investigado, é importante mencionar algumas características do contexto de investigação, objetivando fornecer elementos que favorecerão, na leitura, interpretação e reflexão dos resultados da pesquisa. 
Experiências de formação inicial e atuação profissional do professor supervisor de estágio... Ayla Cristine Gonçalves • Adelar Aparecido Sampaio • Evandra Hein Mendes • Arestides Pereira da Silva Júnior

Marechal Cândido Rondon é um município com características e cultura germânica, de porte médio, localizado no Oeste do Paraná, com população estimada de 53.495 habitantes de acordo com o Instituto Brasileiro de Geografia e Estatística (IBGE, 2020). Na Educação Básica, de acordo com os dados do Instituto Nacional de Estudos e Pesquisas Educacionais Anísio Teixeira (INEP, 2019), no município existem 7 escolas privadas, 12 escolas públicas estaduais e 25 escolas públicas municipais (incluindo 8 Centros Municipais de Educação Infantil - CEMEIs).

\section{Decisões Metodológicas}

Trata-se de uma pesquisa exploratória com abordagem quali-quantitativa (GIL, 2010), tendo em vista que, considerando as características do contexto desta pesquisa, esse delineamento metodológico integrado possibilitará a complementariedade na análise do objeto de estudo, no intuito de ampliar e aprofundar as discussões, assim como dar indicativos de sua reprodutibilidade para outras pesquisas.

A população do estudo é compreendida por professores de EF do município de Marechal Cândido Rondon - Paraná, que supervisionaram ECS em escolas públicas no ano de 2019. Ressalta-se que a totalidade dessa população é compreendida por 17 professores, sendo 07 da rede estadual e 10 da rede municipal.

Todos esses professores foram convidados a participarem da pesquisa, mas 05 deles não retornaram o convite. Dessa forma, a amostra foi constituída por 12 professores que aceitaram participar, correspondendo a 70,6\% da população total, sendo 07 da rede municipal (05 do sexo feminino e 02 do sexo masculino) e 05 da rede estadual de ensino (02 do sexo feminino e 03 do sexo masculino). Todos os participantes foram informados sobre os objetivos e procedimentos da pesquisa e assinaram o Termo de Consentimento Livre e Esclarecido, requisito indispensável para participação. Para manter a privacidade e o sigilo deles, optou- 
Experiências de formação inicial e atuação profissional do professor supervisor de estágio... Ayla Cristine Gonçalves • Adelar Aparecido Sampaio • Evandra Hein Mendes • Arestides Pereira da Silva Júnior

-se por identificar os professores supervisores da rede municipal como PM1 a PM7, e os professores da rede estadual de PE1 a PE5.

Para a obtenção dos resultados, foi aplicado um questionário composto de questões fechadas de múltipla escolha no intuito de identificar, de forma objetiva e quantitativa, a predisposição dos resultados, além de questões abertas complementares, com a finalidade de aprofundar, de forma qualitativa, na compreensão do fenômeno investigado. $\mathrm{O}$ instrumento foi elaborado pelos pesquisadores conforme orientações de Hill e Hill (2008), quanto aos seus objetivos, as seções, como escrever as perguntas, respostas e escalas de medida, o layout e a avaliação.

Como forma de aprimoramento e validação do instrumento, o questionário foi enviado para apreciação de professores especialistas na área com titulação mínima de doutor, os quais avaliaram a clareza, pertinência e relevância. Considerando o retorno dos professores, com suas avaliações e contribuições, os resultados apontaram índices iguais ou superiores a $80 \%$ nos três quesitos, o que os tornaram válidos, conforme recomendações de CasseppBorges (2010).

A princípio, foi encaminhado um ofício a todas as escolas públicas de Marechal Cândido Rondon que receberam estagiários de EF oriundos de uma Instituição de Ensino Superior pública, solicitando a autorização para a realização da pesquisa com os professores em questão. Também foram encaminhados ofícios para a Secretaria de Educação de Marechal Cândido Rondon e ao Núcleo Regional de Educação, solicitando a autorização para realização da pesquisa nos estabelecimentos da rede de ensino municipal e estadual, sendo estes aprovados. Ressalta-se que a coleta de dados foi realizada no ano de 2019.

Após as devidas autorizações concedidas, em acordo com a disposição do Ministério da Saúde, a partir das normas e diretrizes do Conselho Nacional de Saúde que regulamentam a pesquisa em seres humanos (466/2012), esta pesquisa foi submetida e aprovada pelo Comitê Permanente de Ética em Pesquisa com 
Experiências de formação inicial e atuação profissional do professor supervisor de estágio... Ayla Cristine Gonçalves • Adelar Aparecido Sampaio • Evandra Hein Mendes • Arestides Pereira da Silva Júnior

Seres Humanos da Universidade Estadual do Oeste do Paraná (UNIOESTE), conforme parecer consubstanciado n. 3.423.424.

Os dados quantitativos coletados foram tabulados com a utilização da estatística descritiva - frequência ( $f$ ) e percentual (\%), com auxílio do programa Microsoft Excel. Os dados qualitativos foram analisados de forma descritiva a partir da técnica de análise de conteúdo, seguindo os procedimentos sugeridos por Laville e Dionne (1999): seleção das informações relacionadas aos objetivos da pesquisa, categorização e quantificação (frequência - $f$ ), interpretação e escrita em forma de texto, confrontando com o referencial teórico. Também serão utilizados quadros e tabelas que facilitarão a visualização e o entendimento dos resultados.

\section{Resultados e discussão}

Para melhor organização do texto, os resultados são apresentados e discutidos de acordo com as seguintes categorias elaboradas a priori: 1) experiências da própria formação inicial; 2) formação e experiências na supervisão de estágio; e 3) dificuldades no processo de supervisão de ECS na EF.

\section{Experiências da própria formação inicial}

Quando se trata da formação inicial dos professores de EF, não se pode deixar de mencionar o papel do professor supervisor, pois, tendo em vista a sua presença na escola, ele pode proporcionar ao futuro professor possibilidades de aplicação prática e contextualizada dos conhecimentos aprendidos na universidade e trabalhados nas aulas de EF. Esse percurso formativo poderá promover o desenvolvimento de metodologias e técnicas de ensino aprendidas durante todo a formação acadêmica, assumindo-se, 
Experiências de formação inicial e atuação profissional do professor supervisor de estágio... Ayla Cristine Gonçalves • Adelar Aparecido Sampaio • Evandra Hein Mendes • Arestides Pereira da Silva Júnior

dessa forma, como ator-autor do processo educativo em que está inserido (SILVEIRINHA, 2011).

Entendem-se que as experiências adquiridas no processo de formação inicial, muitas vezes são internalizadas pelo professor e utilizadas como parâmetro na sua função de professor supervisor de ECS, ou seja, a experiência que ele teve na formação inicial é considerada na construção do habitus profissional do professor. De acordo com Benites, Cyrino e Souza Neto (2013), muitos professores supervisores se embasam nas suas experiências anteriores e acabam tendo como premissa transmitir elementos práticos para os estagiários. Por esse motivo, é importante compreender como foi a formação inicial dos participantes da pesquisa, sabendo que essa experiência pode ter influência na atuação da supervisão do ECS.

Dessa forma, na tabela 1, os resultados apresentam a avaliação sobre o ECS na formação inicial dos professores supervisores, ou seja, os participantes da pesquisa foram questionados sobre como foi o ECS na época da formação inicial (graduação).

Tabela 1 - Avaliação sobre o ECS na formação inicial

\begin{tabular}{|l|c|}
\hline Respostas & $\mathbf{f}(\mathbf{\%})$ \\
\hline Excelente & $2(16,7 \%)$ \\
\hline Ótimo & $5(41,7 \%)$ \\
\hline Bom & $4(33,3 \%)$ \\
\hline Razoável & $1(8,3 \%)$ \\
\hline Ruim & 0 \\
\hline
\end{tabular}

Fonte: Elaborado pelos autores (2021).

Através dos resultados, é possível constatar que grande parte dos professores $(91,7 \%)$ considera que o ECS, na época da formação inicial, foi bom, ótimo ou excelente. Algumas justificativas são destacadas, como: PM2: "Acompanhamento do professor supervisor de estágio e muitas orientações que colaboraram para a minha formação"; PE4: "Supervisionado por ótimos professores universitários, bem como por professores escolares"; PM7: "Como eu não tinha 
Experiências de formação inicial e atuação profissional do professor supervisor de estágio... Ayla Cristine Gonçalves • Adelar Aparecido Sampaio • Evandra Hein Mendes • Arestides Pereira da Silva Júnior

nenhuma experiência, o estágio supervisionado foi de grande valor. Obtive experiência com os alunos e muita ajuda do professor supervisor da Unioeste". Apenas um professor (8,3\%) relatou que o ECS foi razoável.

De forma geral, considerando as respostas e justificativas, os professores consideraram a sua experiência do ECS na formação inicial de forma positiva e significativa, dando indícios de que, possivelmente, apresentaram reflexos desse processo formativo para a sua atuação profissional junto aos estagiários. Tal avaliação vai ao encontro do que Tardif (2014) argumenta sobre a constituição da profissão docente a partir de quatro pilares: os saberes da formação profissional, os saberes disciplinares, os saberes curriculares e os saberes experienciais, que são construídos no decorrer do seu cotidiano. Nesse sentido, os professores desenvolvem sua condição de profissionais tanto pela sua formação inicial na graduação quanto por suas experiências com a prática docente, iniciada na graduação e concretizada no trabalho das redes de ensino (GATTI, 2014).

Nessa direção, é importante que as disciplinas vinculadas ao ECS dos cursos de formação de professores considerem aspectos que permitam aos estagiários refletirem sobre suas ações e funções, tendo em vista que, futuramente, eles exercerão esse importante papel de acompanhar, orientar e supervisionar os acadêmicos no seu campo de atuação prático - a escola (PIMENTA; LIMA, 2012). Assim constataram-se que, mesmo sendo uma avaliação mais geral do ECS, os participantes da pesquisa enfatizaram e creditaram a importância e eficácia do estágio ao fato de que tiveram um bom acompanhamento e supervisão dos professores supervisores (BENITES et al., 2012).

Na sequência, foram questionados sobre a avaliação que faziam dos professores que supervisionaram o estágio na sua época de formação inicial, apresentados por meio da tabela 2, a seguir: 
Experiências de formação inicial e atuação profissional do professor supervisor de estágio... Ayla Cristine Gonçalves • Adelar Aparecido Sampaio • Evandra Hein Mendes • Arestides Pereira da Silva Júnior

Tabela 2 - Avaliação sobre a supervisão do professor supervisor na formação inicial

\begin{tabular}{|l|c|}
\hline Respostas & $\mathbf{f ( \% )}$ \\
\hline Excelente & $2(16,7 \%)$ \\
\hline Ótimo & $4(33,3 \%)$ \\
\hline Bom & $5(41,7 \%)$ \\
\hline Razoável & 0 \\
\hline Ruim & $1(8,3 \%)$ \\
\hline \multicolumn{2}{|c|}{ Fonte: Elaborado pelos autores (2021). }
\end{tabular}

Da mesma forma, a avaliação referente aos professores supervisores foi positiva, predominando conceitos como "bom" (41,7\%), "ótimo" (33,3\%) e "excelente" (16,7\%), contudo, houve apenas um professor (8,3\%) que considerou como "ruim". Destacam-se alguns comentários que foram feitos em relação ao processo de supervisão, como: PM3: "Tive ótima supervisão, com professores que me orientavam e auxiliavam no estágio"; PE2: "Acompanhou sempre que possivel as aulas e realizando as orientações necessárias"; PE4: "Sempre presentes nas escolas em que atuei, auxiliavam nas dúvidas".

As respostas e justificativas apresentadas vão ao encontro das considerações de Benites (2012) ao enfatizar que o professor supervisor acrescenta em suas tarefas a responsabilidade de auxiliar futuros professores em suas experiências didático-pedagógicas. Nesse sentido, o papel do professor supervisor é de suma importância, pois orienta, norteia e coordena os trabalhos pedagógicos da disciplina na escola, possibilitando aos estagiários um exemplo a ser seguido, e que possivelmente será refletido futuramente na sua atuação profissional em EF.

Na mesma direção, Benites (2012) e Silva Júnior (2016) reforçam que o professor supervisor é aquele que "abre as portas da escola", acolhe o aluno, auxilia, contribui, avalia e principalmente, ampara o acadêmico nos momentos de dificuldade, tentando esclarecer as dúvidas e fazendo com que o aluno reflita sobre sua prática, quais pontos estão adequados e/ou quais devem ser aprimorados. 
Experiências de formação inicial e atuação profissional do professor supervisor de estágio... Ayla Cristine Gonçalves • Adelar Aparecido Sampaio • Evandra Hein Mendes • Arestides Pereira da Silva Júnior

Benites, Cyrino e Souza Neto (2013) observam que o trabaIho do professor supervisor se assemelha ao de um artesão que aprendeu o seu ofício por meio do fazer e ensina pela mesma dinâmica. No entanto, esses autores apresentam uma crítica ao dizer que é necessário pensar na formação, nas práticas e nos saberes desses professores supervisores, de forma a "sair da lógica de ensinar e se aventurar na lógica do formar" (p. 23), ou seja, faz-se necessário um formato que possibilite uma formação adequada a esses professores para que a sua contribuição no processo formativo dos estagiários seja efetiva e coerente com os pressupostos educacionais da atualidade.

Ainda sobre a sua própria formação inicial, os professores relataram pontos positivos e negativos no processo de supervisão de estágio realizada pelo professor de EF da escola (professor supervisor) durante a sua formação inicial (graduação). No quadro a seguir, estão apresentados os principais pontos positivos e negativos apontados pelos participantes:

Quadro 1 - Pontos positivos e negativos no processo de supervisão

\begin{tabular}{|c|c|}
\hline Positivos & Negativos \\
\hline Troca de experiência & Inexperiência \\
Boa orientação & Insegurança \\
Diálogo & Falta de orientação \\
\hline
\end{tabular}

Fonte: Elaborado pelos autores (2021).

Presumem-se que os aspectos mencionados no processo de supervisão durante a sua formação inicial poderão refletir na atuação como professor supervisor de ECS, tendo em vista as experiências vivenciadas e a possibilidade de se "colocar no lugar" do estagiário e entender a dinâmica do processo formativo do futuro professor de EF. No entanto, é importante frisar que as respostas obtidas para essa questão se restringem a apresentar os pontos positivos e negativos e não estabelecem uma relação direta de 
Experiências de formação inicial e atuação profissional do professor supervisor de estágio... Ayla Cristine Gonçalves • Adelar Aparecido Sampaio • Evandra Hein Mendes • Arestides Pereira da Silva Júnior

causa e efeito entre experiências formativas e atuação como professor supervisor.

Nesse sentido, Silva Júnior (2016) reforça que as inúmeras experiências vivenciadas pelo professor, seja na sua formação inicial ou continuada, poderão auxiliar os professores supervisores no acompanhamento e orientação dos futuros professores de EF durante a realização do ECS. Em consonância, Resende et al. (2013) afirmam que os professores supervisores são uma referência fundamental de todo o processo de estágio na perspectiva dos estagiários, sendo vistos como práticos conhecedores da realidade no terreno do ensino em EF, tornando mais fácil e gratificante a adaptação à atividade de ensino.

\section{Avaliação do ECS na formação de professores de EF}

A avaliação do ECS é de suma importância para a sua efetividade no processo formativo do futuro professor de EF. Nesse sentido, Silva Júnior (2016) afirma a necessidade de manter uma avaliação frequente e contínua entre os pares, sobretudo em relação aos professores supervisores, buscando verificar o que vem dando certo e o que precisa ser melhorado.

Nesse sentido, os professores foram unânimes em reconhecer a importância do ECS para a formação, visto que é um processo de aprendizagem que possibilita o acadêmico a vivenciar a realidade escolar e o ambiente de trabalho. Isso ficou evidente em alguns comentários dos professores supervisores, dos quais destacam-se: PE2: "É um momento em que o estagiário vivencia de maneira prática e efetiva o futuro local de trabalho"; PM5: "A vivência no ambiente escolar, bem como o preparo e a regência das aulas são muito importantes para a formação acadêmica".

De acordo com Scalabrin e Molinari (2013), a finalidade da prática de ECS é a de desenvolver em cada estudante dos cursos de licenciatura não apenas a compreensão das teorias estudadas du- 
Experiências de formação inicial e atuação profissional do professor supervisor de estágio... Ayla Cristine Gonçalves • Adelar Aparecido Sampaio • Evandra Hein Mendes • Arestides Pereira da Silva Júnior

rante a graduação, mas também a sua aplicabilidade e a reflexão sobre a prática que se inicia nesse momento. No entanto, Silva Júnior (2016) alerta que o ECS não é elemento isolado ou único no processo de formação do professor de EF, devendo se considerar os demais componentes para o fortalecimento da qualidade formativa docente.

Nesse sentido, Bisconsini e Oliveira (2018) destacam a importância da Prática como Componente Curricular (PCC), como possibilidade de proporcionar a articulação entre as disciplinas do curso de forma que favoreça a aproximação do acadêmico com a escola. À vista disso, a PCC poderá colaborar no fortalecimento e eficácia do ECS, considerando que essa ação de preparação ocorre desde o início da graduação.

Em outra questão, os professores foram questionados se tiveram alguma capacitação/formação para assumir esse importante papel na realização do ECS. Foi possível verificar que nenhum dos professores supervisores participantes da pesquisa teve alguma formação ou capacitação para assumir a supervisão, conforme destacado por PE3 ao afirmar que "seria importante uma formação específica para a atuação [...]. O que nos ajuda são os anos de práti$\mathrm{ca}^{\prime}$ ", assim como o PM1 ao relatar que "nesse momento levo em consideração o bom acompanhamento que tive do professor supervisor durante a minha graduação [...]. Nesse sentido, uma forma de capacitação deve ser pensada para ajudar no processo". Os resultados corroboram os achados de Benites et al. (2012), pois estes afirmaram que os professores supervisores, além de não terem benefícios e incentivos administrativos, também não possuem uma formação específica para exercer essa função, o que provoca uma certa insegurança e desmotivação para atuar ativamente no processo de acompanhamento, orientação e supervisão do ECS.

No intuito de possibilitar um trabalho de formação continuada como forma de superar tais desafios, Benites, Cyrino e Souza Neto (2013) apresentam uma experiência bem sucedida, realizada no município de Rio Claro - SP, onde foi desenvolvido um curso de extensão, com carga horária de 60 horas, para professores su- 
Experiências de formação inicial e atuação profissional do professor supervisor de estágio... Ayla Cristine Gonçalves • Adelar Aparecido Sampaio • Evandra Hein Mendes • Arestides Pereira da Silva Júnior

pervisores e outros professores de EF, cujo objetivo foi discutir, refletir e repensar aspectos da formação, como saberes, práticas pedagógicas e o entendimento sobre a docência, bem como sobre a responsabilidade pela formação de futuros professores, evidenciando a relevância do processo de supervisão, orientação, acompanhamento e avaliação no estágio, realizado de forma colaborativa.

Embora os resultados desta pesquisa evidenciem que os professores não receberam um processo de formação específica, destaca-se, mesmo assim, que $66,7 \%$ se sentem capacitados para exercerem essa função e 33,3\% em parte, como apontado na tabela 3, a seguir.

Tabela 3 - Sentem-se capacitados para exercer a função de professor supervisor

\begin{tabular}{|l|c|}
\hline Respostas & $\mathbf{f ( \% )}$ \\
\hline Sim & $8(66,7 \%)$ \\
\hline Em partes & $4(33,3 \%)$ \\
\hline Não & 0 \\
\hline
\end{tabular}

Fonte: Elaborado pelos autores (2021).

Alguns comentários foram relatados em relação à essa questão: PE1: "Sinto-me capacitado por todas as situações já vivenciadas, pelos meus vinte e cinco anos de sala, acompanhando o crescimento dos alunos"; PE3: "Falta uma capacitação. A única experiência que eu tenho é de ser professora há anos"; PM4: "Após anos como professora supervisora acabamos aprendendo com a prática"; PM6: "Acredito ter capacidade pelos anos de graduação e experiências que tive".

Os resultados vão ao encontro da pesquisa de Benites, Cyrino e Souza Neto (2013), na qual relatam que os professores supervisores se reconhecem como importantes na formação dos futuros professores e ressaltam a sua experiência como a base para o acompanhamento, orientação e supervisão. Azevedo e Andrade (2010) relatam que os professores formadores podem reconstruir os saberes de orientação mediante as necessidades observadas e sentidas nos alunos. Nesse sentido, entende-se que a experiência 
Experiências de formação inicial e atuação profissional do professor supervisor de estágio... Ayla Cristine Gonçalves • Adelar Aparecido Sampaio • Evandra Hein Mendes • Arestides Pereira da Silva Júnior

pode significar ações formadoras, não no sentido do enquadramento de modelos ideais de ser professor, mas como construtoras de posturas, no sentido de abertura para diversidade de relações e propostas de formação pedagógica.

Uma relação paralela entre o estilo inovador de orientar e a tríade professor formador-aluno-contextos formativos, refletida e redimensionada nos próprios cursos de formação, potencializa uma formação que conduz o professor formador na construção e reelaboração dos saberes docentes e de orientação, além do potencial futuro professor a uma prática baseada na reflexão permanente (AZEVEDO; ANDRADE, 2010). Desse modo, assinalam-se que, tanto os saberes docentes quanto os saberes de orientação, precisam ser entendidos como inerentes para a ação profissional dos professores formadores, no intuito de progredir de forma coletiva, conjunta, sistemática, servindo e sendo servido pela própria retroalimentação dos processos formativos que forem vividos.

Nesse direcionamento, Benites et al. (2012) advertem a necessidade de se pensar a proposta de uma formação pedagógica aos professores supervisores, de forma que promova a qualidade e eficácia do processo formativo, não se restringindo unicamente aos "achismos" e subjetividades individuais de suas experiências profissionais, as quais poderão ser limitadoras nesse rico processo de formação.

\section{Dificuldades no processo de supervisão de ECS na EF}

Considerando a complexidade desse espaço formativo e sua importância no processo de preparação do futuro professor, os participantes da pesquisa foram questionados se sentem alguma dificuldade no processo de supervisão de ECS na EF, destacando principalmente os seguintes relatos: PE3: "Sim, por falta de saber quais os pontos a serem cobrados"; PM1: "Eu penso que o professor da universidade precisa vir mais na escola, para conversarmos mais 
Experiências de formação inicial e atuação profissional do professor supervisor de estágio... Ayla Cristine Gonçalves • Adelar Aparecido Sampaio • Evandra Hein Mendes • Arestides Pereira da Silva Júnior

sobre a prática pedagógica"; PM7: "Minha dificuldade é quando não tenho hora-atividade antes ou depois do horário de estágio, pois gosto de ver e conversar sobre as atividades que serão aplicadas, assim como questionar o estagiário sobre as dificuldades encontradas ao término da aula".

Constataram-se algumas dificuldades dos professores supervisores e, a partir dos apontamentos apresentados, verificamos que é significativo aos docentes das escolas receberem uma formação e terem uma troca de experiência com os colegas da área (BENITES; CYRINO; SOUZA NETO, 2013). Relacionado à aproximação entre o professor supervisor e o professor orientador, Pimentel e Pontuschka (2014) reiteram que, no ECS, deve haver proximidade entre os agentes da escola e os da universidade. Portanto, pelo fato de permitir a aproximação dos dois espaços de formação do acadêmico, é proporcionada a troca de conhecimento entre os professores da universidade e os professores supervisores.

A relação entre a universidade e as escolas de educação básica vem se apresentando como um dos aspectos mais frágeis do ECS. A maior parte das dificuldades refere-se a duas questões principais: a ausência da institucionalização dos estágios, dificultando o estabelecimento de parcerias mais efetivas com as escolas, e as possibilidades de acompanhamento implantadas em função das condições institucionais estabelecidas, tais como: o número de estudantes por professor para acompanhamento; o acesso/ deslocamento às escolas-campo de estágio; o acolhimento e o acompanhamento dos estagiários pelas escolas e seus profissionais, principalmente nos cursos noturnos; a demanda de trabalho dos profissionais das escolas e das instituições de ensino superior (MIRA; ROMANOWSKI, 2012).

Entendemos que tais questões dificultam também a própria possibilidade de um acompanhamento e de uma orientação do estágio supervisionado pelos profissionais da escola, na perspectiva de um trabalho conjunto com a universidade. Contudo, uma possível alteração desse quadro situa-se na questão do entendimento do estágio como parceria efetiva entre a universidade e a escola. 
Experiências de formação inicial e atuação profissional do professor supervisor de estágio... Ayla Cristine Gonçalves • Adelar Aparecido Sampaio • Evandra Hein Mendes • Arestides Pereira da Silva Júnior

Com isso, acreditamos também que a escola e seus profissionais possam ter a possibilidade de se perceber e atuar como instituição e profissionais formadores.

Nesse sentido, é importante mencionar o Programa Residência Pedagógica, vinculado ao Ministério da Educação, como importante ação integradora e articulada entre universidade e escola, com ações de imersão do acadêmico na instituição escolar, acompanhadas por um professor experiente da educação básica, que contribuirá no processo formativo do futuro professor. Esse programa faz parte da Política Nacional de Formação de Professores e vem ganhando destaque como uma ação no contexto da formação e qualificação profissional docente no cenário nacional (BRASIL, 2019). Embora o Programa Residência Pedagógica seja uma ação de grande relevância para a formação inicial e continuada, ressalta-se a necessidade de maior valorização de políticas públicas no Brasil que prezem pela qualidade, abrangência e direcionamento de estratégias direcionadas ao professor supervisor e na educação em geral.

Também se recomenda a necessidade da ampliação de iniciativas com realização de atividades/ações formativas e de capacitação pedagógica, assim como o estabelecimento de parcerias entre universidades e escolas que considerem a função do professor da escola como determinante e essencial na formação do futuro professor.

\section{Conclusão}

Considerando a realidade dos professores supervisores de ECS de EF das escolas públicas de Marechal Cândido Rondon, os resultados desta pesquisa reforçam o importante papel desses profissionais como agentes de relevante valor no processo de formação dos futuros professores de EF a partir de sua experiência e inserção no contexto escolar. 
Experiências de formação inicial e atuação profissional do professor supervisor de estágio... Ayla Cristine Gonçalves • Adelar Aparecido Sampaio • Evandra Hein Mendes • Arestides Pereira da Silva Júnior

Constataram-se que os professores, em sua maioria, tiveram boas experiências em relação ao ECS durante a sua própria formação inicial e avaliaram esse momento formativo de forma positiva. Tal indicativo expressa uma possível influência benéfica para a sua atuação como professor supervisor de estágio, tendo em vista que as boas experiências e práticas vivenciadas na formação inicial tendem a internalizar e serem replicadas durante a trajetória profissional, embora não tenha sido objetivo da pesquisa estabelecer uma relação de causa e efeito entre as "boas experiências formativas" e a "atuação efetiva e colaboradora" na supervisão do ECS.

Da mesma forma, evidenciou-se uma avaliação positiva e consensual sobre a importância do ECS na formação de professores de $E F$, sobretudo destacando aspectos vinculados à experimentação e vivência no ensino de conhecimentos no contexto de aplicação da EF escolar. No entanto, uma das maiores fragilidades apontadas é a falta de um processo de formação específica para o professor supervisor. Essa constatação evidenciada na pesquisa vai ao encontro de uma lacuna apresentada em pesquisas relacionadas ao ECS na formação de professores, não se restringindo, portanto, apenas à EF. Nesse sentido, faz-se necessário repensar e fortalecer a formação do professor supervisor, iniciando com ações que mostrem ao acadêmico, na formação inicial, a sua importância e atribuições ao mesmo tempo em que existam ações diretas com o professor supervisor, por iniciativas da universidade, da escola ou dos demais órgãos e sistemas educacionais envolvidos, no intuito de capacitá-los para exercerem o seu papel de supervisor de ECS de forma efetiva e colaborativa.

Mesmo com a limitação da falta de uma formação específica, os professores participantes do estudo se sentem capacitados para exercer a função, tendo em vista a experiência acumulada ao longo da trajetória profissional. Nesse sentido, alerta-se que, ao mesmo tempo em que a experiência é um elemento determinante e apropriado para fomentar o ensino e as reflexões pedagógicas, não deve ser entendida como o único fio condutor nesse processo formativo, fazendo-se necessária a realização de diversas propos- 
Experiências de formação inicial e atuação profissional do professor supervisor de estágio... Ayla Cristine Gonçalves • Adelar Aparecido Sampaio • Evandra Hein Mendes • Arestides Pereira da Silva Júnior

tas de formação pedagógica aos professores supervisores de ECS, como, por exemplo: cursos, eventos, seminários, capacitações, palestras, especializações, dentre outros.

A partir dos resultados evidenciados nesta pesquisa, que se restringiu a uma realidade e com a utilização de questionário, recomenda-se a realização de novas investigações em outras realidades e com a utilização de outros instrumentos que possam ampliar a análise sobre o professor supervisor de ECS em EF.

Em relação às contribuições desta pesquisa, destacam-se: a) os professores supervisores participantes tiveram a oportunidade de refletir sobre o seu papel no processo formativo dos futuros professores de EF; b) proporcionará aos demais professores supervisores de ECS em EF a possibilidade de refletir sobre as suas práticas e ter parâmetros para comparações; e c) a publicação dos resultados servirá de apoio para o fortalecimento das pesquisas direcionadas a esse foco em específico (que ainda são bastante restritas).

Por fim, embora esta pesquisa tenha centrado na investigação em relação ao ECS na formação de professores de EF, além do papel do professor supervisor da escola, é importante destacar que esses são elementos fundamentais e indispensáveis para a qualidade no processo de formação inicial de professores, mas que não são os únicos nesse processo. Nesse sentido, é importante não perder o foco de um olhar mais ampliado e que considere outros elementos, como: a legislação que rege o sistema educacional, a estrutura das redes de ensino, os currículos dos cursos de formação de professores, a realidade das escolas, os agentes envolvidos, dentre outros.

\section{Referências}

AROEIRA, K. P. Estágio Supervisionado e possibilidades para uma formação com vínculos colaborativos entre a universidade 
Experiências de formação inicial e atuação profissional do professor supervisor de estágio... Ayla Cristine Gonçalves • Adelar Aparecido Sampaio • Evandra Hein Mendes • Arestides Pereira da Silva Júnior

e a escola. In: ALMEIDA, M. I.; PIMENTA, S. G. (Orgs.), Estágio Supervisionado na formação docente: educação básica e educação de jovens e adultos. São Paulo: Cortez, 2014. p. 113-150. AZEVEDO, M. A. R.; ANDRADE, M. F. R. Os professores formadores e os saberes de orientação mediante ações tutorais. Educação, Porto Alegre, v. 33, n. 3, p. 213- 221, set./dez. 2010.

\section{BENITES, L. C. O professor-colaborador no estágio curricular} supervisionado em educação física: perfil, papel e potencialidades. 2012. 180 f. Tese (Doutorado) Programa de pós-graduação em ciências da motricidade (pedagogia da motricidade humana). Universidade Estadual Paulista, Instituto de Biociências de Rio Claro, 2012.

BENITES, L. C. et al. Qual o papel do professor colaborador no contexto do estágio curricular supervisionado na educação física? Revista Brasileira de Ciência e Movimento, Brasília, v. 20, n. 4, p. 13-25, 2012.

BENITES, L. C.; CYRINO, M.; SOUZA NETO, S. Estágio curricular supervisionado: a formação do professor-colaborador. Olh@res, Guarulhos, v. 1, n. 1, p. 116-140, 2013.

BISCONSINI, C. R.; OLIVEIRA, A. A. B. A Prática como Componente Curricular na formação inicial de professores de Educação Física. Movimento, Porto Alegre, v. 24, n. 2, p. 455-470, 2018.

BRASIL. Ministério da Educação. Coordenação de Aperfeiçoamento de Pessoal de Nível Superior - CAPES. Port. GAB n. 259, de 17 de dezembro de 2019. Dispõe sobre o regulamento do Programa de Residência Pedagógica e do Programa Institucional de Bolsa de Iniciação à Docência (PIBID). Brasília, DF, 2019.

CASSEPP-BORGES, V.; BALBINOTTI, M. A. A.; TEODORO, M. L. M. Instrumentação psicológica: fundamentos e práticas. Porto Alegre: Artmed, 2010.

COSTA FILHO, R. A. Professores iniciantes de educação física: discussões a partir das fontes de autoeficácia docente. 
Experiências de formação inicial e atuação profissional do professor supervisor de estágio... Ayla Cristine Gonçalves • Adelar Aparecido Sampaio • Evandra Hein Mendes • Arestides Pereira da Silva Júnior

2014. 124 f. Dissertação (Mestrado em Ciência da Motricidade). Universidade Estadual Paulista, Rio Claro, 2014.

GATTI, B. A formação inicial de professores para a educação básica: as licenciaturas. Revista USP, São Paulo, n. 100, p. 33-46, 2014.

GIL, A. C. Como elaborar projetos de pesquisa. São Paulo: Atlas, 2010.

HILL, M. M.; HILL, A. Investigação por questionário. $2^{\mathrm{a}} \mathrm{Ed}$. Lisboa: Edições Sílabo, 2008.

IBGE. Instituto Brasileiro de Geografia e Estatística. Cidades. 2020. Disponível em: https://cidades.ibge.gov.br/brasil/pr/marechal-candido-rondon/panorama. Acesso em: 20 mai. 2021.

INEP. Instituto Nacional de Estudo e Pesquisas Educacionais Anísio Teixeira. Sinopses Estatísticas da Educação Básica, 2019. Disponível em: http://portal.inep.gov.br/web/guest/sinopses-estatisticas-da-educacao-basica. Acesso em: 20 mai. 2021.

LAVILLE, C.; DIONNE, J. A construção do saber: manual de metodologia da pesquisa em ciências humanas. Belo Horizonte: Artmed, 1999.

MIRA, M. M., ROMANOWSKI, J. P. A relação universidade-escola no estágio supervisionado do curso de pedagogia: desafios e possibilidades. Revista Entrever, Florianópolis, v. 2, n. 3, p. 184-199, jul./dez. 2012.

MORAES, E. V. et al. O estágio supervisionado nos cursos de graduação em Educação Física: um desafio presente nesta formação. Dialogia, São Paulo, v. 7, n. 2, p. 199-209, 2008.

NEIRA, M. G. Proposições para o estágio disciplinar na formação de professores de Educação Física. In: NASCIMENTO, J.; FARIAS, G. O. (Orgs), Construção da identidade profissional em Educação Física: da formação a intervenção. Florianópolis: Editora da Udesc, 2012.

PIMENTEL, C. S.; PONTUSCHKA, N. N. A construção da profissionalidade docente em atividades de estágio curricular: experiências 
Experiências de formação inicial e atuação profissional do professor supervisor de estágio... Ayla Cristine Gonçalves • Adelar Aparecido Sampaio • Evandra Hein Mendes • Arestides Pereira da Silva Júnior

na Educação Básica. In: ALMEIDA, M. I.; PIMENTA, S. G. Estágio Supervisionado na formação docente: educação básica e educação de jovens e adultos. São Paulo: Cortez, 2014. PIMENTA, S. G.; LIMA, M. S. L. Estágio e docência. 7. ed. São Paulo: Cortez, 2012.

RESENDE, R. et al. A percepção dos professores cooperantes sobre os conhecimentos e as competências dos estudantes. Revista Educação Física/UEM, Maringá, v. 24, n. 4, p. 519-533, 2013.

SAMPAIO, A. A. S. et al. Realização e desenvolvimento pessoal e profissional em estudantes de educação física. Caderno de Educação Física e Esporte, Marechal Cândido Rondon, v. 17, n. 1, p. 1-8, 2019.

SAMPAIO, A. A.; STOBAUS, C. D. O apoio pedagógico na formação inicial: perspectivas para o bem-estar docente e desenvolvimento profissional. Espaço Pedagógico, Passo Fundo, v. 22, n. 2, p. 371391, jul./dez. 2015.

SCALABRIN, I. C.; MOLINARI, A. M. C. A importância da prática do estágio supervisionado nas licenciaturas. Revista Científica, São Paulo, v.7, n. 1, p. 1-12, 2013.

SILVA JÚNIOR, A. P. Configurações e relações estabelecidas no Estágio Curricular Supervisionado na formação inicial de professores de Educação Física. 2016. 232 f. Tese (Doutorado em Educação Física) Programa de Pós-Graduação Associado em Educação Física - UEM/UEL, 2016.

SILVA JÚNIOR, A. P. et al. Estágio curricular supervisionado na formação de professores em educação física: uma análise da legislação a partir da resolução CFE n 03/1987. Pensar a Prática, Goiânia, v. 19, n. 1, p. 1-14, 2016.

SILVA JÚNIOR, A. P.; OLIVEIRA, A. A. B. Estágio curricular supervisionado na formação de professores de educação física no Brasil: uma revisão sistemática. Movimento, Porto Alegre, v. 24, n. 1, p. 77-92, 2018. 
Experiências de formação inicial e atuação profissional do professor supervisor de estágio... Ayla Cristine Gonçalves • Adelar Aparecido Sampaio • Evandra Hein Mendes • Arestides Pereira da Silva Júnior

SILVEIRA, G. C.; BATISTA, P. M.; PEREIRA, A. L. O perfil do professor cooperante no contexto da supervisão de estágio profissional: um estudo de revisão sistemática da literatura. Revista da Educação Física/UEM, Maringá, v. 25, n.2, p. 309-321, 2014. SILVEIRINHA, M. C. R. C. A formação inicial percepcionada pelos professores cooperantes. 2011. 435 f. Tese (Doutorado em Educação) - Departamento de Ciências da Educação, Universidade de Aveiro, 2011.

TARDIF, M. Saberes docentes e formação profissional. 17 ed. Petrópolis: Vozes. 2014.

TELLES, C. et al. As contribuições do Estágio Curricular Supervisionado para a aprendizagem docente dos professores-colaboradores da educação básica na percepção de acadêmicos/ estagiários de Educação Física. Revista Eletrônica Fafit, Itararé, v. 6, n. 1, p. 1-7, 2015.

\section{PUBLISHER}

Universidade Federal de Goiás. Faculdade de Educação Física e Dança. Publicação no Portal de Periódicos UFG. As ideias expressadas neste artigo são de responsabilidade de seus autores, não representando, necessariamente, a opinião dos editores ou da universidade. 